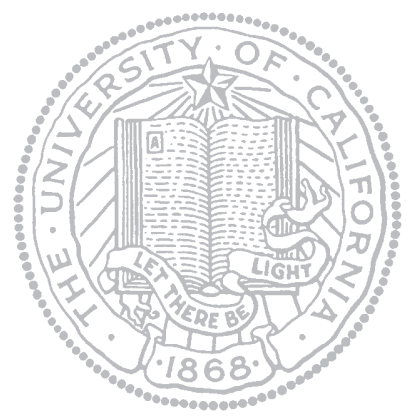

UNIVERSITY OF

CALIFORNIA

Division of Agriculture

and Natural Resources

http://danrcs.ucdavis.edu
PUBLICATION 8002

\section{Easy On-Site Tests for Fungi and Viruses in Nurseries and Greenhouses}

JOHN N. KABASHIMA, Ornamental Horticulture Farm Advisor, UC Cooperative Extension, Orange County; JAMES D. MACDONALD, Professor and Plant Pathologist, Department of Plant Pathology and Agricultural Experiment Station, UC Davis; STEVE H. DREISTADT, Senior Writer, IPM Education and Publications, Statewide IPM Project, UC Davis; and DIANE E. ULLMAN, Professor, Department of Entomology, UC Davis.

$\mathbf{T}$ o manage a disease effectively, you often have to determine which specific pathogens are present. Many control actions are effective only against certain pathogens; if you do not correctly identify the cause of unhealthy plants, your control actions may be ineffective, resulting in plant damage and wasting time and money. Fortunately, easy-to-use test kits can help you determine whether or not certain plant pathogens are present so you can make an informed decision. This publication describes test kits that identify some common plant viruses and root and crown decay fungi. You can use kits to test for certain viruses infecting aboveground parts of virtually any plant. Some kits that detect root-infecting fungi are recommended for greenhouse and container-grown nursery plants. Using special procedures not discussed here, you can also use these kits to test for the same fungi in water and container media. The Phytophthora test kit has also been used in field soil assays and tests of field crops, but neither of these uses is currently recommended.

\section{ROOT AND CROWN DECAY FUNGI}

Phytophthora, Pythium, and Rhizoctonia are common root and crown decay fungi that affect many different plants. Dull, yellow, or wilted leaves are often the first symptoms noticed in plants affected by these fungi. Infected plants become stunted and die when their roots and crowns decay. Similar symptoms are caused by other pathogens, insects, and noninfectious disorders, so specific diagnosis can be difficult.

Fungal fruiting bodies such as spores and sclerotia are used to identify many pathogens, but Phytophthora and Pythium species produce no fruiting bodies visible to the naked eye. Rhizoctonia may form coarse weblike growths around rotted basal stems, but the tan-white fungal mycelia are neither consistently present nor reliably indicative, and other fungal species also produce whitish mycelia. In the past, to confirm the specific fungal species present you would have to send a sample of suspect tissue to a plant pathologist who would culture it on laboratory media and examine it under a microscope. The process would typically take 1 to 3 weeks.

\section{TOSPOVIRUSES}

Tomato spotted wilt virus (TSWV) and impatiens necrotic spot virus (INSV) are important viruses spread by thrips. These viruses in the genus Tospovirus have wide, overlapping host ranges, and damage many agricultural and ornamental crops. Tospoviruses produce a broad range of symptoms, including stunting, yellow or white spotting, black or brown stem or leaf necrosis, ringspots, defoliation, vein necrosis, and dark or yellow line patterns, mottling, or mosaic. 
For field diagnosis of viruses, growers commonly rely on recognition of damage symptoms, consultation of published lists of host plants, and knowledge of local disease history and how specific viruses develop and spread. Visual diagnosis of viruses, however, is often inaccurate. Symptoms vary by cultivar. Some plants serve as hosts for many different viruses. Multiple viruses can occur in a plant at the same time. Viral symptoms can easily be confused with the symptoms of nutritional disorders, herbicide damage, or diseases caused by bacteria or fungi. Some infected plants can be symptom-free for many weeks, showing symptoms only when the crop matures. Symptom-free plants can be a source of infection for nearby crops.

Electron microscope analysis is the traditional method for expert diagnosis of viruses. However, electron microscopes are expensive, results take at least several days, similar viruses often cannot be microscopically distinguished, and few diagnosticians are available to perform this work. You can also use plant indicator series or bioassays to diagnose viruses, either by rubbing a solution from symptomatic plant tissue onto different indicator plants known to develop specific symptoms in reaction to certain viruses or by using their insect vectors for transmission. Indicator series are relatively slow, and necessitate the constant production of the indicator plants, and sometimes the insect vectors, that the bioassays require.

\section{PATHOGEN TEST KITS}

Now, instead of sending samples to a laboratory and waiting for answers, you can use quick and relatively simple, commercially available test kits to identify certain pathogens. Most of these field-useable test kits employ a serological technique called ELISA (enzyme-linked immunosorbent assay). This technology is routinely used in home pregnancy tests, blood tests for AIDS and hepatitis, and sampling for pesticide residues. Fungal test kits, sold under the brand name Alert, can detect Phytophthora, Pythium, and Rhizoctonia. The QTA-Tospo brand test kits can diagnose impatiens necrotic spot virus and tomato spotted wilt virus. Other test kits are available that detect other fungi, certain bacteria (e.g., pathovars of Xanthomonas campestris), and many viruses, and new kits are constantly being introduced. Contact your local Cooperative Extension advisor or product suppliers for the latest information on pathogen test kits.

A separate kit is available for each fungal genus and each tospovirus. You can run multiple tests at the same time. Each kit contains all necessary materials, including detector devices sensitized with antibodies that recognize and react with proteins from the target plant pathogen. Some test kits require refrigeration and must be used before an expiration date printed on the packaging.

\section{USING THE ELISA TEST KITS}

Test kits for Phytophthora, Pythium, and Rhizoctonia fungi can confirm pathogen presence in as little as 10 minutes. First you collect tissue samples from the suspect plants, then you macerate them by grinding between abrasive pads, and treat them as shown in figure 1. After you complete the sample treatment procedure, a visible color-change reaction in the detector device will indicate infection. A "positive control" dot will darken to indicate that the test kit is working properly. If the target fungus is present in the sample, the "pathogen detection" dot will also darken. If the pathogen detection dot does not darken, the target fungus is not present in the plant sample. 
The virus test kits require more skill and patience than the root decay test kits. Virus kits must be used at a clean workbench area with running water. Samples must be set aside for hour-long incubation periods between certain steps (figure 2).

\section{Phytophthora and Pythium Test Kits}

The Alert test kit for Phytophthora has been used to detect all common Phytophthora species. Pathogen detection can be accomplished when as little as 0.5 percent of a plant's roots are infected. The Phytophthora test does not react with other common soilborne fungi, including species of Fusarium, Mortierella, Trichoderma, Rhizoctonia, Rhizopus, and Sclerotinia.

Exercise caution when interpreting test results. Pestalotia spp. may react weakly with the Phytophthora kit. These fungi mostly cause blight (spotting, dieback, and
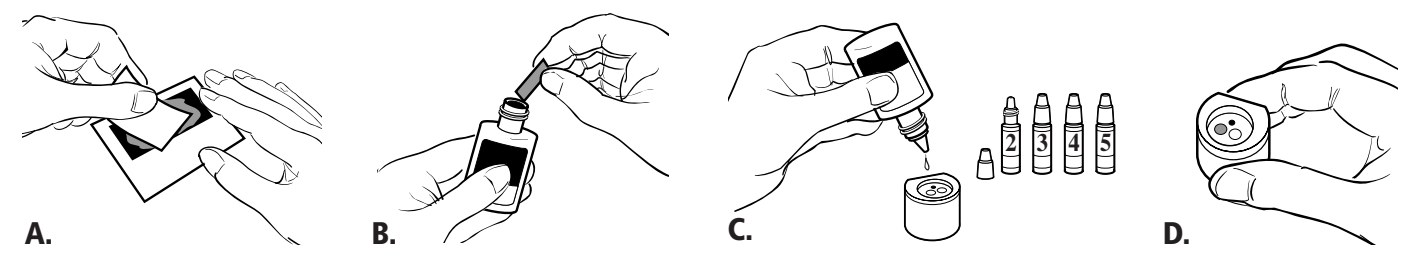

Figure 1. Tests for Phytophthora, Pythium, and Rhizoctonia root and crown decay fungi can be performed on-site by growers in about 10 minutes: (A) collect and grind samples using abrasive pads; (B) fold pads and insert them into the extraction solution; (C) apply solutions to detector; (D) examine detector dots for color change. Illustrated here is the Alert root decay test kit from Neogen Corporation.
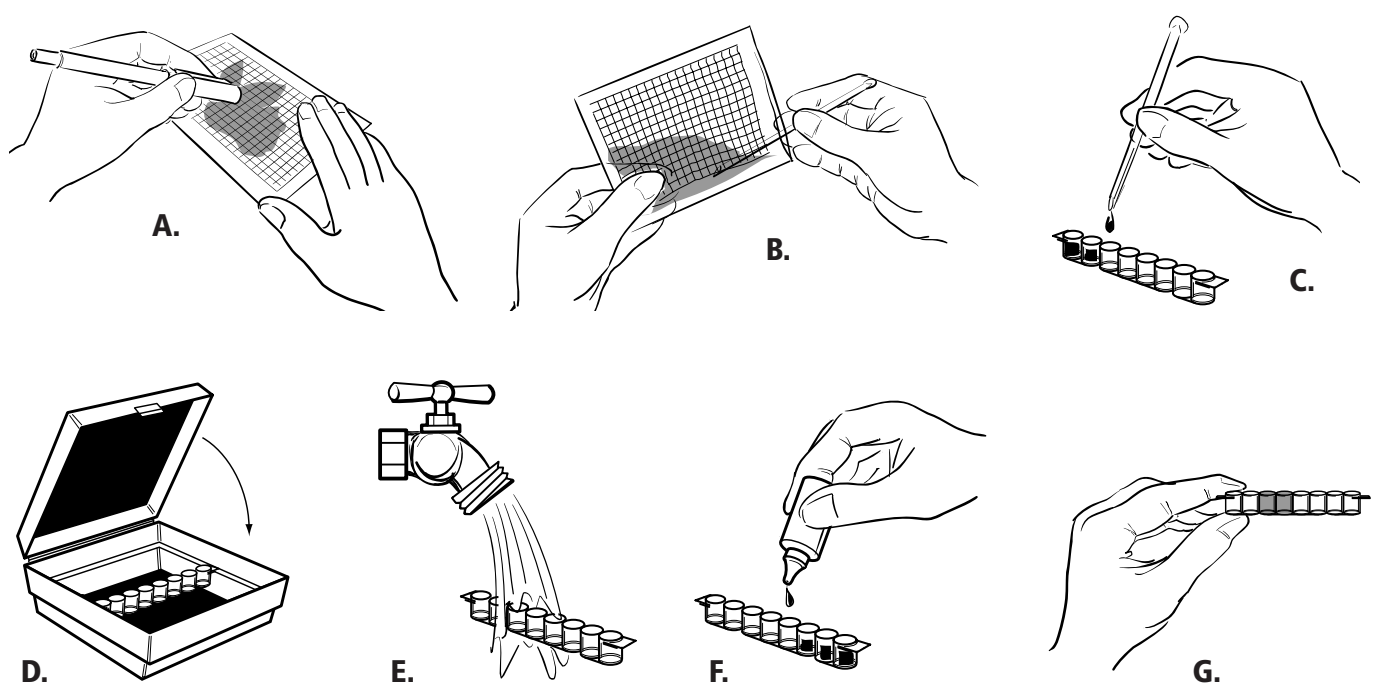

Figure 2. On-site plant virus test kits for tomato spotted wilt and impatiens necrotic spot provide results within several hours. The methods for use are detailed in information from the suppliers, and are summarized here: (A) place symptomatic plant tissue into the mesh-lined pouch provided with the kit and crush the sample by placing the pouch on a hard surface and rubbing it with the blunt end of a pen; (B) insert a pipette-like plastic straw into the pouch and collect liquefied plant material; (C) place sample drops into a plastic well, which is on a strip with other wells for additional samples and controls without liquid to help ensure accurate results; (D) place the plastic well strip into a container with a moistened paper towel and allow the samples time to react with a coating on the inside of the wells; $(E)$ after 1 hour, rinse the wells with water, then $(F)$ add special solution and place the well strip into the moist container for another hour. Repeat this last rinse, fluid addition, and wait procedure; (G) after 30 to 60 minutes, if the target virus is present, a visible color change occurs in the test wells. Illustrated here is a QTA-Tospo kit test from Agdia, Inc. 
decay) of aboveground parts of trees, woody shrubs, and vines, so you may need to use characteristic damage symptoms, plant parts affected, and host lists to help you distinguish Pestalotia spp. from root decay fungi.

Pythium and Phytophthora are closely related fungi, and at high concentrations they can cross-react (i.e., Pythium may cause a positive reaction on a Phytophthora kit, and vice versa). In fact, a few Pythium species do not react at all with the Pythium kit and react only with the Phytophthora kit. We recommend running both tests on the same samples because the tests complement each other. These cross-reactions generally are not a problem, since cultural and chemical controls are the same for Phytophthora and Pythium. If some sort of regulatory decision is involved, however, you may require more-exacting follow-up tests.

\section{Rhizoctonia Test Kit}

Use the greatest caution with the Rhizoctonia test. Rhizoctonia solani is an aggressive pathogen, but many other Rhizoctonia species are not. Some Rhizoctonia species are beneficial mycorrhizal fungi, and many are simply common soil fungi involved with the decomposition of organic matter. The Alert Rhizoctonia test does not currently distinguish between $R$. solani and other Rhizoctonia species. Since nonpathogenic types may colonize fine roots, complete reliance on this test could result in a mistaken diagnosis.

Consider limiting use of the Rhizoctonia test to bench-grown crops, including most greenhouse and shadehouse plants. Use kits on plants less than a year old that have not contacted unsterilized soil, since these plants are less likely to be colonized by nonpathogenic Rhizoctonia spp. Limit tissue sampling to lower stem and crown tissues to avoid the fine roots that can be colonized by nonpathogenic Rhizoctonia spp.

\section{Collecting Root Decay Samples}

Good sampling technique is critical to effective use and interpretation of ELISA tests. Strive to collect only tissues that have recently been infected by the primary decay pathogen. By taking samples from the leading edge of an infection next to healthy tissue, you maximize the possibility of detecting the primary decay pathogen. A test that involves severely rotted tissue is usually a waste of time and test kits.

Remove the test plant from its container and examine the root system to determine which part of the plant to sample. Start by examining for necrosis in the lower stem and crown area. If this area is healthy, knock or wash away some soil to expose major roots and examine these for necrosis. Keep working down until you detect transitional (healthy-infected) tissue, and then collect a sample for testing that includes both apparently healthy tissue and adjoining necrotic tissue. When you are testing for decay fungi, your most reliable results will generally come from sampling infected crown or major root tissue. Always test more than one plant using separate kits before you base treatment actions on test results. Wash your hands thoroughly or wear and discard disposable gloves after handling diseased plants to avoid spreading plant pathogens on hands.

\section{WHEN TO USE TEST KITS}

ELISA test kits reliably determine whether target pathogens are present. Use the kits to test plants whenever you suspect a pathogen infection. The test kit is only one tool in an overall disease monitoring program, but test kits can be highly cost effective, compared to the costs of unnecessary or wrong treatments, late control actions, or damaged crops. 
Besides diagnosing the cause of poor plant health, on-site test kits are useful for regular monitoring for viruses in symptom-free plants of susceptible crops. You might also consider using root decay test kits as part of routine monitoring, so long as you practice good sampling methods and observe the cautions presented here. In particular, you might consider a regular testing program for "mother blocks" and areas where cuttings or other new plants are received or shipped out for propagation. Routine testing can be especially useful when plants are young; most crops are more severely affected by pathogens if plants are infected during early growth.

Be aware that negative results in a specific ELISA test do not rule out the possibility that another pathogen is causing disease. You can also get negative results if you sample and test the wrong tissue. When testing for viruses, sample the youngest symptomatic leaves. When testing for decay fungi, collect samples from the leading edge of an infection, where apparently healthy tissue and infected tissue meet. Accurate diagnosis of certain problems may require other tests, including the sampling of water or media. Many tests can be performed only by an outside laboratory or are commonly performed off-site, such as indicator plant series bioassays for many viruses other than INSV and TSWV.

\section{Tospovirus Test Kits}

The regular sampling of symptom-free plants for the presence of virus can be very beneficial when you are working with propagation material or crops that are highly susceptible, serve as symptom-free carriers of virus, or tend to develop delayed symptoms. On-site test kits allow growers to detect and confirm virus presence more quickly than is possible with outside laboratory tests. For propagators and growers of sensitive crops that will benefit from frequent testing, the on-site tests can be more economical than an outside laboratory.

\section{Virus Indicator Plants}

Indicator plants are easy to use for detecting the presence of thrips that can transmit tospoviruses. Although we do not detail the methods here, you can use indicator plants in combination with test kits. Indicator plants are used because they quickly develop blackish lesions when an infectious thrips feeds on their leaves, so they reveal when and where infectious thrips occur in growing areas. The petunias 'Burgundy Madness' and 'Blue Carpet' are good indicator plants for INSV and TSWV according to University of California research. Dark lesions develop on leaves of these petunias within about 2 to 4 days after feeding by infectious thrips. Indicator plants that detect virus presence in thrips are distinct from the test kits or the previously mentioned plant indicator series used to identify the virus species in crop plants. Indicator plants and test kits are complementary tools that can be used together in an overall virus monitoring program.

\section{Root Decay Test Kits}

Kits for detecting fungi were not developed and optimized for presymptomatic detection of disease. Exercise caution if you use test kits for routine monitoring to help you to decide whether or not root decay pathogens are developing, even though symptoms are not apparent. Since all Phytophthora species are plant pathogens, the regular sampling and testing of root tips in the bottom 1 or 2 inches of the root ball of container plants may work well for Phytophthora. Many Pythium and Rhizoctonia species are weak pathogens or are nonpathogenic, however. These non-pathogenic fungi commonly colonize very fine roots or dead roots killed by improper irrigation, solar heating of containers, or other causes. Before you base your root decay treatment decisions upon the results of tests on asymptomatic plants, draw on other information collected in an overall disease monitoring program. 
Besides their use confirming the presence of infected plant tissue and possible routine monitoring use in crops, ELISA tests can detect root decay fungi in water and soil. Water tests can be especially important when you are using surface or recycled water for irrigation. Water or soil testing may require special sampling techniques; for more information, contact your Cooperative Extension advisor or agricultural product supplier.

\section{ESTABLISHING AN OVERALL DISEASE MONITORING PROGRAM}

You can use test kits in combination with other information to make good pest management decisions. Learn which pathogens can attack the crops you are growing. Scout the crops regularly (at least weekly) for signs and symptoms of disease. Each time that you monitor for root disease, select at least a few plants from different areas of each crop and remove the plants from their containers or gently scrape or wash away the soil. Examine the roots and crowns for browning, softness, or other early indications of disease. Also inspect aboveground parts for discoloration or wilting and fungal growths, which may indicate more advanced stages of disease.

Understand the conditions and practices that promote diseases and regularly scout for and remedy disease-promoting conditions and practices. Poor sanitation, inadequate drainage, and improper irrigation are primary conditions promoting root decay. Where virus is a concern, use yellow sticky traps (or possibly blue traps for thrips) throughout growing areas to provide early detection of insect vectors. Routinely scout growing areas and remove alternate hosts and reservoirs of disease and insect vectors, including weeds, crop residue, and old plants that will not be marketed.

\section{SUGGESTED READING}

Ali-Shtayeh, M. S., J. D. MacDonald, and J. Kabashima. 1991. A method for using commercial ELISA tests to detect zoospores of Phytophthora and Pythium species in irrigation water. Plant Disease 75: 305-311.

MacDonald, J. D., J. Stites, and J. Kabashima. 1990. Comparison of serological and culture plate methods for detecting species of Phytophthora, Pythium, and Rhizoctonia in ornamental plants. Plant Disease 74: 655-659.

Xia, J. Q., C. L. Sutula, and D. B. Marti. 1996. Development of a greenhouse test for tomato spotted wilt virus and impatiens necrotic spot virus. Acta Horticulturae 431: 193-198. 


\section{SOME SUPPLIERS AND DISTRIBUTORS}

Agdia, Inc.

30380 County Road 6

Elkhart, IN 46514

phone: 1-800-622-4342 or (219) 264-2014

World Wide Web:http://www.agdia.com

Gempler's, Inc.

211 Blue Mounds Road

P.O. Box 270

Mt. Horeb, WI 53572

phone: 1-800-382-8473 or (608) 437-4883

World Wide Web:http://www.gemplers.com

Neogen Corporation

620 Lesher Place

Lansing, MI 48912

phone: 1-800-234-5333 or (517) 372-9200

World Wide Web:http://www.neogen.com

\section{UC IPM WORLD WIDE WEB SITE}

University of California Statewide IPM Project

World Wide Web:http://www.ipm.ucdavis.edu

To simplify information, trade names of products have been used. No endorsement of named products is intended, nor is criticism implied of similar products that are not mentioned.

An electronic version of this publication is available on the DANR Communication Services website at http://danrcs.ucdavis.edu.

\section{Publication 8002}

(C)1997 by the Regents of the University of California,

Division of Agriculture and Natural Resources.

The University of California, in accordance with applicable Federal and State law and University policy, does not discriminate on the basis of race, color, national origin, religion, sex, disability, age, medical condition (cancer-related), ancestry, marital status, citizenship, sexual orientation, or status as a Vietnam-era veteran or special disabled veteran. The University also prohibits sexual harassment.

Inquiries regarding the University's nondiscrimination policies may be directed to the Affirmative Action Director, University of California, Agriculture and Natural Resources, 300 Lakeside Drive, 6th Floor, Oakland, CA 94612-3560 (510) 987-0096. 